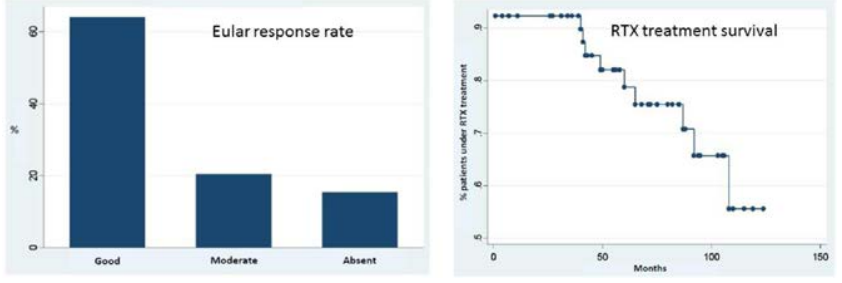

was good in $64 \%(n=25)$, reaching remission in $17(31 \%)$ of the patients, and moderate response in $21 \%(n=8)$ of them (Figure 1$)$. Only $2(4 \%)$ patients were treated with GCC at the end of the follow-up, $p<0,00001$ compared to baseline. The daily dose of PDN at the end of follow-up was $6 \mathrm{mg}$ in a case and $12 \mathrm{mg}$ in the other, $p=00001$ compared to baseline. At the end of the follow-up $24 \%$ of the patients $(n=13)$ changed or discontinued the drug: 9 changed due to secondary failure, 2 suspended due to adverse events, 1 due to death due to prior neoplastic process and 1 due to complete disease remission. Survival at 1, 2, 3, 4, 5, 6 and 7 years was $92 \%, 92 \%, 82 \% 78 \%, 75 \%, 75 \%$ and $65 \%$ respectively; with a mean survival rate of 90 months (Figure 1).

Conclusion: The results of our analysis show that patients with RA undergoing RTX treatment have adequate control of disease activity and drug survival rates, like published data. RTX treatment allowed stopped GCC treatment in 31 cases (90\%).

REFERENCES:

[1] Oldroyd AGS, et al. Rheumatology (Oxford). 2018 Jun 1;57(6):1089-1096. Disclosure of Interests: Gonzalo Jurado Quijano: None declared, Lola Fernández de la Fuente Bursón: None declared, Blanca Hernández-Cruz Speakers bureau: Sociedad Española de Reumatología, Abbvie, Roche, Bristol, MSD, Lilly, Pfizer, Amgen, Sanofi, Consultant of: Abbvie, Lilly, Sanofi, STADA, UCB, Amgen, Grant/research support from: Fundación para la Investigación Sevilla, Junta de Andalucía, Fundación Andaluza de Reumatología, Paloma Muñoz Reinoso: None declared, Vicente Merino Bohóquez: None declared, José Javier Pérez Venegas: None declared

DOI: 10.1136/annrheumdis-2021-eular.1362

\section{AB0214 \\ SURVIVAL, EFFICACY AND SAFETY OF GOLIMUMAB IN PATIENTS WITH RHEUMATOID ARTHRITIS AND SPONDYLOARTHRITIS: DATA FROM AN ARGENTINEAN COHORT}

C. A. Isnardi ${ }^{1}$, E. E. Civit De Garignani ${ }^{2}$, A. García Ciccarelli ${ }^{2}$, J. Sanchez Alcover $^{2}$, R. Garcia Salinas ${ }^{3}$, S. Magri ${ }^{3}$, E. Albiero ${ }^{4}$, C. Gobbi ${ }^{4}, E^{2}$ Velozo ${ }^{5}$, E. Soriano ${ }^{6}$, M. Brom ${ }^{6}$, J. Zacariaz ${ }^{6}$, I. Strusberg ${ }^{7}$, M. Baravalle ${ }^{7}$, S. Castaños ${ }^{7}$, L. Morales ${ }^{7}$, S. Paira ${ }^{8}$, R. Calvo ${ }^{8}$, A. Ortiz $^{8}$, R. Perez Alamino ${ }^{9}$, H. Maldonado Ficco ${ }^{10}$, G. Citera ${ }^{1}{ }^{1}$ Psychophysical Rehabilitation Institute, Rheumatology, DQG, Argentina; ${ }^{2}$ Hospital El Carmen, Rheumatology, Godoy Cruz, Argentina; ${ }^{3}$ Hospital Italiano La Plata, Rheumatology, La Plata, Argentina; ${ }^{4}$ Sanatorio Allende, Rheumatology, Córdoba, Argentina; ${ }^{5}$ Sanatorio Adventista del Plata, Rheumatology, Libertador San Martín, Argentina; ${ }^{6}$ Hospital Italiano de Buenos Aires, Rheumatology, Ciudad de Buenos Aires, Argentina; ${ }^{7}$ Instituto Strusberg, Rheumatology, Córdoba, Argentina; ${ }^{8}$ Hospital Provincial Dr. José María Cullen, Rheumatology, Santa Fe, Argentina; ${ }^{9}$ Hospital Dr. Nicolás Avellaneda, Rheumatology, San Miguel de Tucumán, Argentina; ${ }^{10}$ Nuevo Hospital Río Cuarto "San Antonio de Padua", Rheumatology, Río Cuarto, Argentina

Background: Golimumab is a human monoclonal antibody directed against TNF $\alpha$ in its soluble and transmembrane forms. It can be used subcutaneously or intravenously and has shown efficacy for use in patients with rheumatoid arthritis (RA), psoriatic arthritis (PSA) and ankylosing spondylitis (AS).

Objectives: The aim of this study was to evaluate the efficacy, safety, and cumulative survival of golimumab in patients with RA, PsA and AS from different rheumatology centers in Argentina.

Methods: We performed a longitudinal study of consecutive adults with RA (ACR/EULAR 2010 criteria), PSA (CASPAR criteria) and AS (ASAS 2009 criteria), who have started treatment with subcutaneous or intravenous golimumab according to medical indication in each center. Data was obtained by review of medical records. Sociodemographic and clinical data, musculoskeletal manifestations, comorbidities, previous treatments were recorded. In reference to golimumab treatment, start date, route of administration and concomitant treatments were identified. Disease activity was assessed using DAS28 for RA patients, DAPSA and MDA for PSA and BASDAI for AS. The presence of adverse events (AE) was recorded. If golimumab was stopped, date and cause was documented. Patients were followed up until golimumab discontinuation, loss of follow-up, or study completion (November 30, 2020). Statistical analysis: $\mathrm{Chi}^{2}$ test or Fischer exact test and T test or Mann Whitney and ANOVA or Kruskal Wallis, as

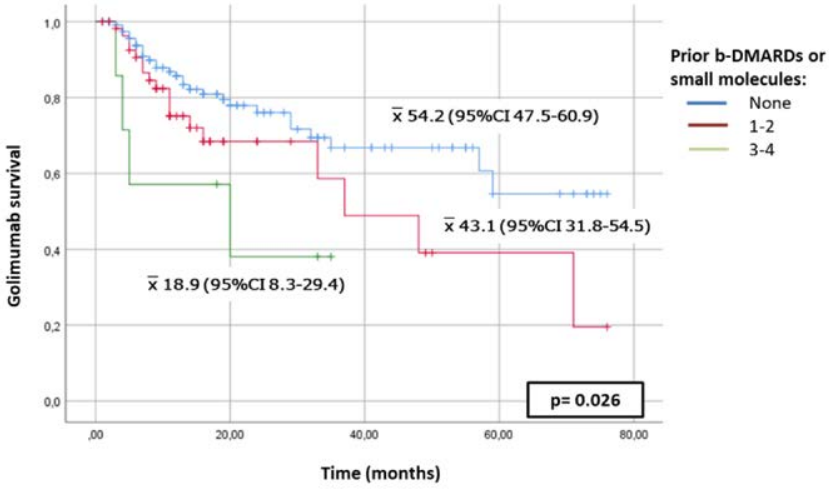

Figure 1. Golimumab survival according to prior b-DMARD o small molecule treatment.

appropriate. The incidence of EA was assessed in events every 100 patient/year. Kaplan-Meier curves and log Rank analysis. Cox proportional regression.

Results: One hundred eighty two patients were included, 116 with a diagnosis of RA, 30 with PsA and 36 with AS. Most of them $(70.9 \%)$ were female with a median $(\mathrm{m})$ age of 55 years (IQR 43.8-64) and $m$ disease duration of 7 years (IQR 4-12.7) at treatment initiation. Al least one prior biological DMARD or a small molecule was received by 63 patients (34.6\%). The most frequent indication cause was conventional DMARD failure. In $94.8 \%$ of the patients Golimumab was administered subcutaneously, and in $80.8 \%$ in association with conventional DMARDs, the most frequently used was methotrexate. Total follow-up was 318.1 patients/year.

Golimumab treatment showed clinical improvement in all three groups of patients. In RA patients DAS28 significantly decreased during the first 12 months of follow-up, m 5.9 (IQR 4.9-6.6) at baseline, 3.8 (IQR 2.6-4.6) at 6 months and 2.8 (IQR 2.1-3.6) at 12 months, $\mathrm{p}<0.0001$. In PsA, m DAPSA-ESR value was 32.2 (IQR 24.2-47.7), 10.1 (IQR 5.8-18.3) and 11.2 (IQR 3.4-24) at baseline, 6 and 12 months, respectably ( $p<0.0001)$. In AS, m BASDAI was 6.2 (IQR 4.8-7.3), 2.8 (IQR 1.7-4.1) and 2.2 (IQR 1.1-3.2), at baseline, 6 and 12 months respectively $(p<0.0001)$.

The incidence of adverse events was 6.6 per 100 patients/year, being infections the most frequents ones. During follow-up, 50 patients $(27.5 \%)$ discontinued golimumab, the most frequent cause was treatment failure $(68 \%)$, followed by lack of health insurance (16\%) and adverse events (10\%). Golimumab persistence was $79 \%$ and $57.6 \%$ at 12 and 24 months, respectively. Treatment survival was 50.2 months $(95 \% \mathrm{Cl} 44.4-55.9)$. Patients who had received prior treatment with biological DMARDs or small molecules showed lower survival (Figure 1). In the multivariate analysis, adjusting for age, sex and disease duration, those patients showed twice the risk of suspending treatment (HR 2.01, 95\% Cl 1.1-3.7).

Conclusion: Golimumab treatment in real life patients in Argentina has shown good efficacy and safety. Drug survival was over 4 years and almost $80 \%$ were still using golimumab after one year. Prior treatment with other b-DMARDs o small molecules was associated with lower treatment survival.

Disclosure of Interests: Carolina Ayelen Isnardi Speakers bureau: Bristol Myers Squibb, Janssen, Grant/research support from: Pfizer, Emma Estela Civit De Garignani Speakers bureau: Abbvie, Novartis, Agustín García Ciccarelli Speakers bureau: Janssen, Novartis, Consultant of: Novartis, Grant/research support from: Janssen, Novartis, Jimena Sanchez Alcover: None declared, Rodrigo Garcia Salinas Speakers bureau: Abbvie, AMGEN, Bristol-Myers Squibb, Eli Lilly, GSK, Janssen Cilag, Montpellier-UCB, Novartis, Roche - Genentech, Sanofi, Merck Serono., Sebastian Magri Speakers bureau: Abbvie, AMGEN, Bristol-Myers Squibb, Eli Lilly, GSK, Janssen Cilag, Montpellier-UCB, Novartis, Roche - Genentech, Sanofi, Merck Serono., Eduardo Albiero Consultant of: Janssen, Carla Gobbi Speakers bureau: Pfizer, Consultant of: Pfizer, Janssen, Edson Velozo Speakers bureau: Janssen, Novartis, Pfizer, Consultant of: Abbvie, Janssen, Novartis, Grant/research support from: Janssen, Novartis, Pfizer, Enrique Soriano Speakers bureau: AbbVie, Novartis, Bristol MS, Novartis, Eli Lilly, Genzyme, Pfizer, Amgen, and Roche, Consultant of: Novartis, AbbVie, Pfizer, Eli Lilly, Sanofi, Sandoz, Amgen., Grant/research support from: Roche, Novartis, AbbVie, Glaxo Smith Kline, BMS, Martín Brom: None declared, Johana Zacariaz Grant/research support from: Bristol Myers Squibb, Ingrid Strusberg Speakers bureau: Gema Biotech SAU, BMS, Abbvie, Consultant of: Gema Biotech SAU, Abbvie, Janssen, Grant/research support from: Abbvie, Lilly, Galápagos, Servier, GSK, Merck Serono, Marcos BARAVALLE Speakers bureau: Montepellier, Consultant of: Abbvie, Janssen, Grant/research support from: Abbvie, Lilly, Galápagos, Servier, GSK, Merck Serono, Sol Castaños Speakers bureau: Abbvie, Lilly, Galápagos, Servier, GSK, Merck Serono, Liliana Morales Speakers bureau: Lilly, Consultant of: Janssen, Grant/research support from: Abbvie, Lilly, Galápagos, 
Servier, GSK, Merck Serono, Sergio Paira: None declared, Romina Calvo: None declared, Alberto Ortiz: None declared, Rodolfo Perez Alamino Speakers bureau: Pfizer, Abbvie, Amgen, Bristol-Myers-Squibb, Lilly, Janssen, Novartis, Hernan Maldonado Ficco Speakers bureau: Pfizer, Abbvie, Jansen, Novartis, Bago, Bristol, Eli Lilly., Consultant of: Pfizer, Abbvie, Novartis, Jansen, Bago, Eli Lilly., Gustavo Citera Speakers bureau: Abbvie, BMS, Lilly, Jansen, Gema, Pfizer, Roche, Grant/research support from: Pfizer

DOI: 10.1136/annrheumdis-2021-eular.1399

\section{AB0215 1 COMPARISON BETWEEN RITUXIMAB ORIGINATOR THERAPY AND ITS BIOSIMILAR IN THE INCIDENCE OF LATE-ONSET NEUTROPENIA IN ADULT PATIENTS WITH RHEUMATOID ARTHRITIS AND OTHER AUTOIMMUNE DISEASES}

M. M. Ahmad ${ }^{1}$, E. Mcrorie ${ }^{1}$. 'Western General Hospital, Rheumatology, Edinburgh, United Kingdom

Background: Late-onset neutropenia (LON) occurs when the absolute neutrophil count drops below $1.5 \times 10(9) / L$ four weeks after Rituximab infusion. ${ }^{1}$ It is a condition recognised more in haematological malignancy patients treated with Rituximab with a reported prevalence of $8 \%$ or higher. ${ }^{2}$ LON was reported in $6.5 \%$ of rheumatological patients ${ }^{1}$, while a French registry found a prevalence of $1.3 \%$ in rheumatoid arthritis patients. ${ }^{3}$

Almost all patients receiving Rituximab originator therapy at our Rheumatology department were switched to its biosimilar starting from November 2017. Our haematology team observed LON cases in their patients after this period.

Objectives: We wanted to establish whether there is increased LON occurrence with the biosimilar than the originator therapy, requiring specific monitoring.

Methods: This is a cross-sectional retrospective review of 12 months period before and after switching to the biosimilar of all patients who received Rituximab for the first time. We reviewed the patients' blood monitoring for up to 12 months after receiving Rituximab. We used a proforma to collect the age, sex, diagnosis, date of the first infusion, use of other DMARDs, LON occurrence within 12 months after the infusion and neutropenia within the 12 months before it in addition to the frequency of the blood monitoring after the infusion.

Results: For the originator, between 1/1/2016 and 31/12/2016, 142 patients received Rituximab, 47 (33.09\%) of them were given the treatment for the first time. Their median age was 62 years, 28 (59.5\%) were females. The most common diagnosis was rheumatoid arthritis $38(80.8 \%)$, and $35(74.4 \%)$ patients were on other disease-modifying agents (DMARDs). Two patients $(4.2 \%)$ developed LON. In both patients, this occurred during admission for septic arthritis whilst on antibiotics, and both had Grade $2: \geq 1,000-<1,500$ / mm3 neutropenia.

For the Biosimilar cohort, between 1/4/2019 and 31/3/2020, 161 patients received Rituximab, $36(22.3 \%)$ of them were given the treatment for the first time. Their median age was 59 years, $27(75 \%)$ of them were females. The most common diagnosis was rheumatoid arthritis $25(69.4 \%)$, and $26(72.2 \%)$ were on other DMARDs. One patient $(2.77 \%)$ developed grade 2 LON one month after Rituximab. Another patient with known autoimmune neutropenia was excluded. In all the Three patients with LON in both groups, neutrophil count recovered in less than a month, and they had normal IgG before the infusion.

The frequency of blood monitoring after Rituximab infusion was done 1-3 monthly in $32(68 \%)$ patients and $23(63.8 \%)$ patients in the originator and biosimilar groups, respectively.

Four $(8.5 \%)$ patients and three (8.3\%) patients in the originator and biosimilar groups respectively had a frequency of blood monitoring done less than six-monthly.

Conclusion: In our patients' cohort, LON incidence following switching to the Rituximab biosimilar was not higher than the originator therapy.

REFERENCES:

[1] Monaco, W. E., Jones, J. D. \& Rigby, W. F. C. Rituximab associated late-onset neutropenia-a rheumatology case series and review of the literature. Clin Rheumatol 35, 2457-2462 (2016).

[2] Dunleavy, K., Tay, K. \& Wilson, W. H. Rituximab-Associated Neutropenia. Seminars in Hematology 47, 180-186 (2010).

[3] Salmon, J. H. et al. Late-onset neutropenia after treatment with Rituximab for rheumatoid arthritis and other autoimmune diseases: data from the Autolmmunity and Rituximab registry. RMD Open 1, e000034 (2015).

Acknowledgements: The authors would like to thank pharmacist Christine Hay for her help in providing the Rituximab databases.

Disclosure of Interests: Mostafa Meshaal Ahmad: None declared, Euan McRorie Speakers bureau: I have spoken at meetings sponsored by Roche several years ago, Consultant of: I have sat on advisory boards for Roche several years ago., Grant/research support from: I was the local investigator for the ORBIT study, published in the Lancet in 2016.

DOI: 10.1136/annrheumdis-2021-eular.1544

\section{AB0216 LONG-TERM RESULTS OF T2T THERAPY INITIATED AT THE ONSET OF RHEUMATOID ARTHRITIS (DATA FROM OREL REGISTRY)}

V. Rybakova ${ }^{1}$, A. Avdeeva ${ }^{2}$, Y. Olyunin ${ }^{2}$, E. Nasonov ${ }^{3,4} .{ }^{1}$ V.A. Nasonova Research Institute of Rheumatology, Outpatient Department, Moscow, Russian Federation; ${ }^{2}$ V.A. Nasonova Research Institute of Rheumatology, Laboratory of Early Arthritis, Moscow, Russian Federation; ${ }^{3}$ V.A. Nasonova Research Institute of Rheumatology, Scientific S, Moscow Russian Federation; ${ }^{4}$ I.M. Sechenov First Moscow State Medical University, Ministry of Health of Russia (Sechenov University), Department of Therapy and Occupational Diseases, Moscow, Russian Federation

Background: Current guidelines for the treatment of rheumatoid arthritis (RA) recommend early administration of methotrexate (MTX) and addition of a biologic if MTX monotherapy does not provide remission or low activity of the disease. Efficacy of this strategy in real clinical practice was assessed using data from the Russian RA registry OREL.

Objectives: To analyze long-term results of intensive treatment initiated at RA onset in real clinical practice.

Methods: 141 RA patients with disease duration less than 3 years $(29$ men, 112 women) were included. 112 were positive for rheumatoid factor and $119-$ for anti-cyclic citrullinated peptide antibody. Subcutaneous MTX was initiated at $10-15 \mathrm{mg}$ per week with further dose escalation up to $20-30 \mathrm{mg}$ per week. Therapy was adjusted every 3 months. If MTX monotherapy did not allow to achieve treatment target of remission or low disease activity, biologics were added.

Results: Median DAS 28 at baseline was $5,31[4,79 ; 6,14]$. Initiation of treatment resulted in steady decrease of disease activity $(p<0.05$, table1). After 1 year of follow-up $33.8 \%$ of patients received MTX monotherapy, 33.8\% - MTX in combination with tumor necrosis factor alpha inhibitors, $22.0 \%-$ MTX +abatacept, $0.55 \%-$ MTX + tocilizumab, $0.47 \%-$ MTX + rituximab. Low disease activity was achieved in $16.3 \%$ patients, and remission - in $45.8 \%$. After 6 years median age of patients was $58[49 ; 66]$ years, disease duration - $84[79$ 89] months, low disease activity was documented in $21.3 \%$, and remission - in $7.8 \%$ of cases (fig. 1). $7 \%$ of patients were able to maintain remission without any treatment. Biologics were discontinued in 15 patients after achieving remission or low disease activity, and synthetic DMARDs - in 5 patients having remission.

Conclusion: Intensive therapy initiated at RA onset demonstrates high effectiveness, allowing $61.5 \%$ of patients to achieve low disease activity or remission within 12 months, and to maintain these results after 6 years of treatment in $29.2 \%$. Adherence to this strategy allowed to discontinue biologics in 15 patients and synthetic DMARDs in 5 patients after achieving treatment target.

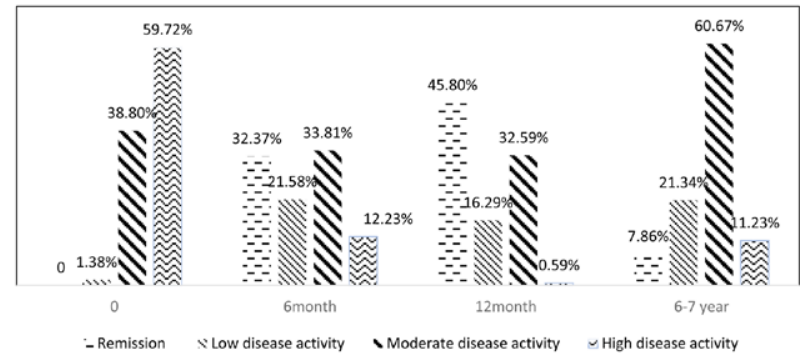

Figure 1. Changes of the disease activity during follow-up

Table 1. Changes of the main inflammatory activity measures, Me $\left[25^{\text {th }}\right.$; $75^{\text {th }}$ percentile]

\begin{tabular}{lccc}
\hline Parametres & $\mathbf{0}$ & $\mathbf{1 2}$ months & 6 years \\
\hline DAS28 & $5,31[4,79 ; 6,14]$ & $2,85[2 ; 3,90]^{*}$ & $4,008[3,4 ; 4,59]^{*}$ \\
SDAl & $28,27[18,79 ; 40,73]$ & $5,67[2 ; 11,98]^{*}$ & $15,06[9,32 ; 21]^{*}$ \\
CDAI & $25[17 ; 36]$ & $5[1,7 ; 11]^{*}$ & $15[9 ; 21]^{*}$ \\
ESR (mm/hr) & $32[19 ; 50]$ & $16[8 ; 30]^{*}$ & $16[10 ; 25]^{*}$ \\
CRP (mg/l) & $26,55[6,4 ; 45,30]$ & $3,85[1,5 ; 11,3]^{*}$ & $2,2[0,9 ; 4,9]^{*}$
\end{tabular}

${ }^{*} \mathrm{p}<0.05$ in all cases.

Disclosure of Interests: None declared

DOI: 10.1136/annrheumdis-2021-eular.1552 